\title{
Preoperative Radiological Parameters to Predict Clinical and Radiological Outcomes after Laminoplasty
}

\author{
Su Hun Lee, Dong Wuk Son, ${ }^{1,2}$ Jun Jae Shin, ${ }^{1}$ Yoon Ha, ${ }^{4}$ Geun Sung Song, ${ }^{1,2}$ Jun Seok Lee, Sang Weon Lee ${ }^{1,2}$ \\ Department of Neurosurgery, Research Institute for Convergence of Biomedical Science and Technology, Pusan National University Yangsan \\ Hospital, Yangsan, Korea \\ Department of Neurosurgery, ${ }^{2}$ School of Medicine, Pusan National University, Busan, Korea \\ Department of Neurosurgery, ${ }^{3}$ Yongin Severance Hospital, Yonsei University College of Medicine, Yongin, Korea \\ Department of Neurosurgery, ${ }^{4}$ Spine and Spinal Cord Institute, Severance Hospital, Yonsei University College of Medicine, Seoul, Korea
}

Many studies have focused on pre-operative sagittal alignment parameters which could predict poor clinical or radiological outcomes after laminoplasty. However, the influx of too many new factors causes confusion. This study reviewed sagittal alignment parameters, predictive of clinical or radiological outcomes, in the literature. Preoperative kyphotic alignment was initially proposed as a predictor of clinical outcomes. The clinical significance of the K-line and K-line variants also has been studied. Sagittal vertical axis, T1 slope (T1s), T1s-cervical lordosis (CL), anterolisthesis, local kyphosis, the longitudinal distance index, and range of motion were proposed to have relationships with clinical outcomes. The relationship between loss of cervical lordosis (LCL) and T1s has been widely studied, but controversy remains. Extension function, the ratio of $\mathrm{CL}$ to T1s (CL/T1s), and Sharma classification were recently proposed as LCL predictors. In predicting postoperative kyphosis, T1s cannot predict postoperative kyphosis, but a low CL/ T1s ratio was associated with postoperative kyphosis.

Key Words : Cervical vertebrae - Laminoplasty - Spinal cord compression - Ossification of posterior longitudinal ligament . Reference values.

\section{INTRODUCTION}

Laminoplasty is an important treatment option for cervical spondylotic myelopathy (CSM) and ossified posterior longitudinal ligament (OPLL) disease. Its long-term clinical and radiological outcomes have also been reported to be excel- lent ${ }^{9,21,48,60)}$. However, some patients have unpredictably poor clinical outcomes after laminoplasty. In this regards, many studies have focused on preoperative sagittal alignment parameters that could predict poor clinical or radiological outcomes. Preoperative cervical kyphotic alignment is the first suggested factor and is also the most important predicting

- Received : October 14, 2020 •Revised : November 11, 2020 •Accepted : December 19, 2020

- Address for reprints : Dong Wuk Son

Department of Neurosurgery, Pusan National University Yangsan Hospital, 20 Geumo-ro, Mulgeum-eup, Yangsan 50612, Korea

Tel : +82-55-360-2126, Fax : +82-55-360-2156, E-mail : md6576@naver.com, ORCID : https://orcid.org/0000-0002-9154-1923

\section{Jun Jae Shin}

Department of Neurosurgery, Yongin Severance Hospital, Yonsei University College of Medicine, 363 Dongbaekjukjeon-daero, Giheung-gu, Yongin 16995, Korea Tel : +82-2-2228-2150, Fax : +82-2-393-9979, E-mail : zunzae@hanmail.net, ORCID : https://orcid.org/0000-0002-1503-6343

This is an Open Access article distributed under the terms of the Creative Commons Attribution Non-Commercial License (http://creativecommons.org/licenses/by-nc/4.0) which permits unrestricted non-commercial use, distribution, and reproduction in any medium, provided the original work is properly cited. 
factor for clinical results after laminoplasty ${ }^{1,58)}$. The K-line also helped clinicians to predict patients' clinical prognosis ${ }^{13)}$. Recent studies have an interest in the loss of cervical lordosis (LCL) because patients could have a kyphotic alignment or Kline (-) after laminoplasty ${ }^{19)}$. In this regard, the T1 slope (T1s) has been spotlighted recently ${ }^{31)}$. However, the influx of too many new predictive factors can cause confusion in the analysis of patients' information ${ }^{61,63)}$. In this study, we present an overview of the sagittal alignment parameters that might predict clinical or radiological results through a literature review.

\section{MATERIALS AND METHODS}

A comprehensive literature search and analysis was performed using the search terms "laminoplasty" and "alignment" in the Embase and PubMed (MEDLINE) databases for peer-reviewed articles published in English. Articles relevant for this review were selected by the authors if they included information on relationships between pre-operative sagittal parameters and clinical or radiological outcomes.

Since this study aims to analyze the sagittal alignment related parameters, the analysis of the following factors was excluded; differences in the surgical technique (open-door, French-door, C3 laminectomy, and extensor muscle-preserving ${ }^{20)}$, surgical devices (sutures, mini-plates, bone grafts, and spacers) ${ }^{25)}$, the most cephalic level (C3 or C4), and indices using axial images of computed tomography (CT) or magnetic resonance image (MRI), such as space available for the spinal $\operatorname{cord}^{32)}$ and the spinal cord compression ratio ${ }^{46)}$.

The analyzed parameters were divided into two categories : 1) preoperative radiological parameters predicting clinical outcomes and 2) preoperative radiological parameters predicting radiological outcomes. The radiological outcomes were divided into (2-a) LCL and (2-b) postoperative kyphosis.

\section{RESULTS}

We included 32 papers which had focused on pre-operative

PRISMA 2009 flow diagram

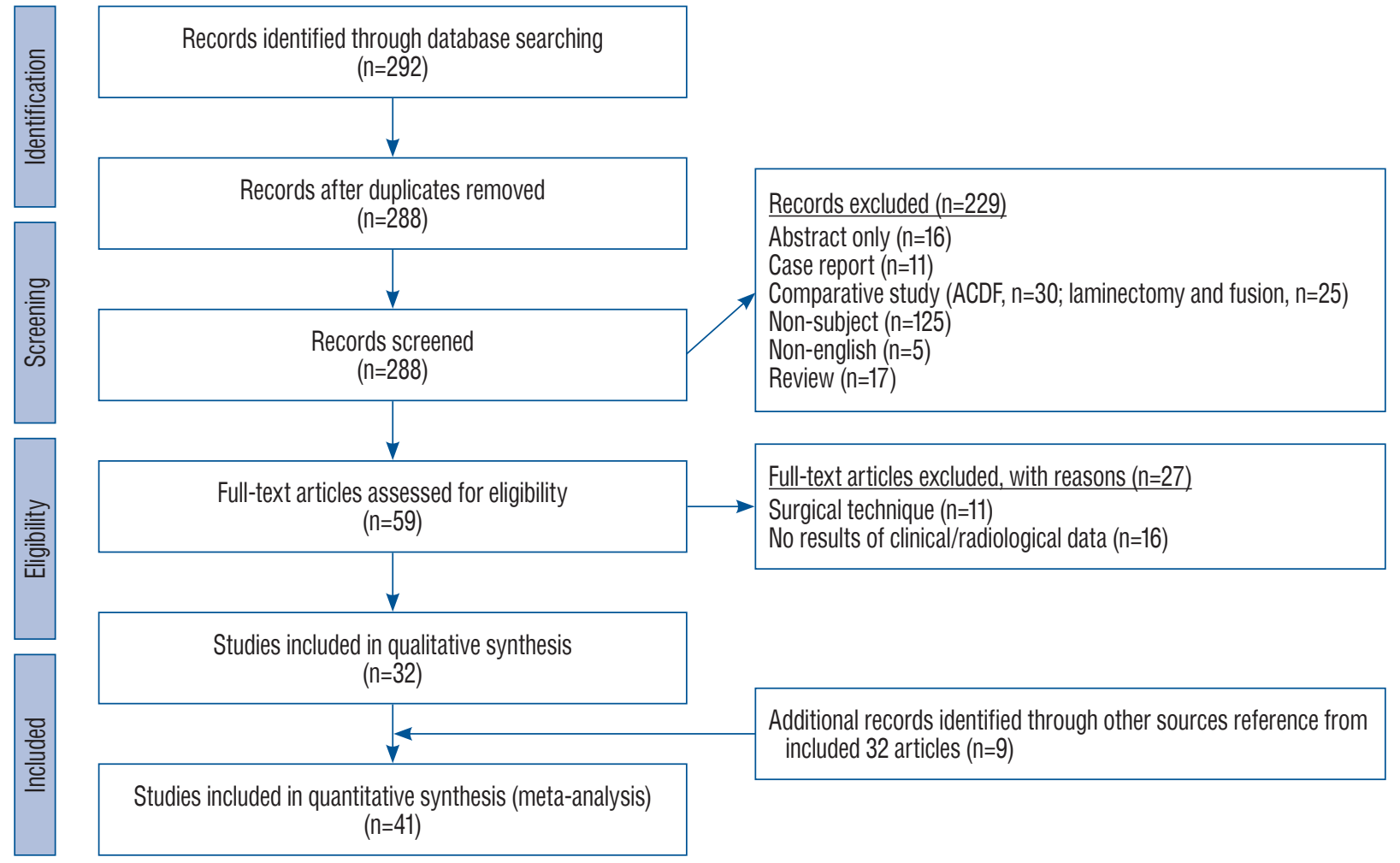

Fig. 1. Flow chart diagram of our search mechanism in accordance to the PRISMA. PRISMA : preferred reporting items for systematic reviews and metaanalyses, ACDF : anterior cervical discectomy and fusion. 
cervical alignment related parameter to predict clinical or radiological outcomes after laminoplasty. In addition, we searched all references of 32 papers, and nine additional papers related to the subject were identified (Fig. 1) ${ }^{2,8-10,21,27,48,64,68)}$.

\section{Pre-operative radiological parameter predicting clinical outcomes}

Most of the indices used for outcome measurement were the Japanese Orthopaedic Association (JOA) scale ${ }^{73)}$ or the modified JOA (mJOA), and the recovery rate $(\mathrm{RR})^{15)}$ were used. The Visual analogue scale (VAS) of neck pain and the Oswestry disability index (ODI) were also used. The disease entity analyzed in each study is indicated next to the subheading. The included parameters and measurement methods are summarized in Table 1 and Fig. 2. Radiological factors related to clinical outcomes are summarized in Table 2.

\section{Pre-operative kyphotic alignment (CSM and OPLL)}

This risk factor was particularly emphasized in laminectomy-only procedures. To obtain a sagittal bowstring effect, preoperative and postoperative lordotic alignment is essential $^{4,5)}$. Because laminoplasty preserves more posterior bony structure than laminectomy, it reduces the postoperative incidence of kyphosis, but it cannot change preoperative kyphosis to lordosis ${ }^{16)}$. In this regard, it was suggested that patients with preoperative kyphotic alignment should not undergo laminoplasty in order to ensure the sagittal bowstring effect. Baba et al. ${ }^{2)}$ demonstrated this relationship in laminoplasty through MRI. Posterior cord migration was significantly correlated with preoperative and postoperative cervical spine lordosis. They also found that posterior cord migration was significantly correlated with neurological improvements, and patients with neurological improvement $(\mathrm{RR}) \geq 50 \%$ had a significantly larger posterior shift.

However, controversy remains regarding the relationship between preoperative kyphosis and clinical outcomes ${ }^{12,18,24,30,34,43,47,72)}$. In a long-term study, Iwasaki et al. ${ }^{21)}$ included OPLL patients with more than 10 years of follow-up. LCL occurred in 55\% of patients, and postoperative kyphotic alignment occurred in $8 \%$ of patients. However, preoperative alignment and alignment changes had no significant effects on neurological deterioration. Ogawa et al. ${ }^{48)}$ also reported no significant difference in the highest postoperative JOA score, RR, or nuchal pain according to preoperative lordotic or kyphotic alignment in OPLL. Additionally, the highest JOA score and RR were not significantly different according to LCL occurrence. Chiba et al. ${ }^{9)}$ analyzed CSM and OPLL patients with more than 10 years of follow-up. They reported that preoperative alignment did not affect the RR in CSM patients, but preoperative kyphotic alignment tended to be related to a lower RR in OPLL

Table 1. The list of enrolled sagittal parameters and measurement method

\begin{tabular}{|c|c|}
\hline & Measurement method \\
\hline $\mathrm{CL}$ & $\begin{array}{l}\text { (Neutral X-ray) Cobb's method: angle between a line drawing the inferior endplate of C2 and another line drawing the inferior } \\
\text { endplate of C7 }\end{array}$ \\
\hline SVA & (Neutral X-ray) horizontal offset between plumb line of the center of C2 and the posterosuperior corner of C7 \\
\hline T1s & (Neutral X-ray) angle between upper endplate of T1 and horizontal reference line \\
\hline T1s-CL & (Neutral X-ray) difference value between $\mathrm{T1}$ slope and CL \\
\hline $\mathrm{CL} / \mathrm{T} 1 \mathrm{~s}$ & (Neutral X-ray) ratio of CL to T1 slope \\
\hline $\mathrm{ROM}$ & (Dynamic X-ray) difference of CL between flexion and extension \\
\hline K-line & (Neutral X-ray or MR) straight-line connects the midpoints of the spinal canal from C2 to C7 \\
\hline mK-line & (MR T1 sagittal) straight-line connects the midpoints of the spinal canal from C2 to C7 \\
\hline Anterolisthesis & (Flexion $\mathrm{X}$-ray) $>3 \mathrm{~mm}$ of anterior vertebral displacement in relation to a below VB \\
\hline Local kyphosis & (Neutral X-ray) angle between forming the maximum local kyphosis \\
\hline LDI & (Neutral X-ray) length of the vertical line between the poster-inferior edge of the C2 and C7 divided by the AP diameter of the C4 \\
\hline EF & (Dynamic X-ray) difference of CL between neutral and extension \\
\hline
\end{tabular}

$\mathrm{CL}$ : cervical lordosis, SVA : sagittal vertical axis, T1s: T1 slope, CL/T1s : ratio of cervical lordosis to T1 slope, ROM : range of motion, mK-line : modified Kline, MR : magnetic resonance image, VB : vertebral body, LDI : Iongitudinal distance index of cervical spine, AP : anterior-posterior, EF: extension function 
(A)

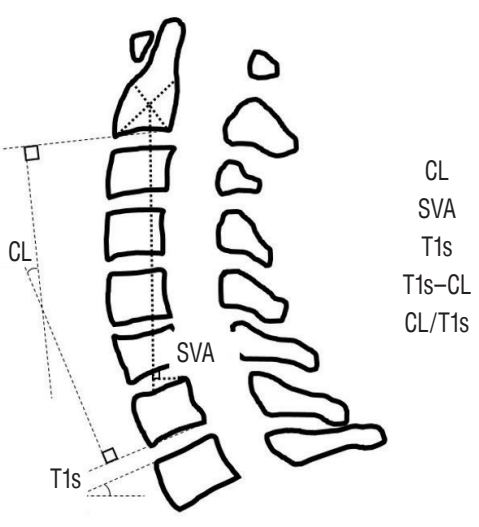

(B)
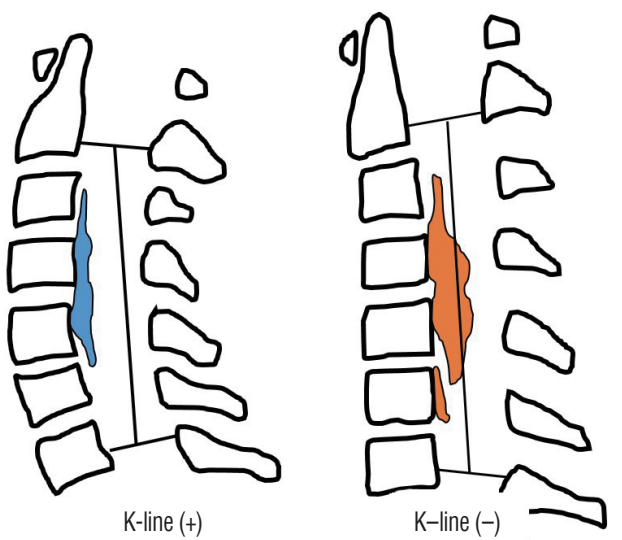

(C)

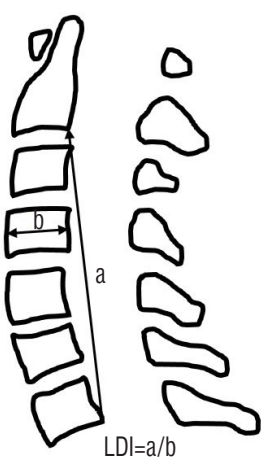

(D)

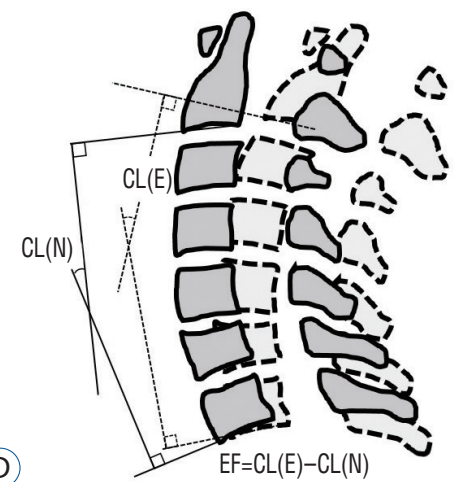

Fig. 2. Schematic images of sagittal radiological parameters. A : Routine sagittal parameters. B : K-line. C : a means length of a vertical line drawn between the postero-inferior edges of $C 2$ and $C 7, b$ means the antero-posterior diameter of $C 4$, and $L D I$ of the cervical spine. $D$ : Extension function (EF). $\mathrm{E}$ : Anterolisthesis in flexion position. CL : cervical lordosis, SVA : sagittal vertical axis, T1s : T1 slope, LDI : longitudinal distance index, CL(N) : cervical lordosis in neutral position, $\mathrm{CL}(\mathrm{E})$ : cervical lordosis in extension position.

patients.

\section{K-line (OPLL), modified K-line (CSM) and variants}

Preoperative alignment is a concept that does not include the size of the OPLL, so it has limitations in predicting clinical results. Fujiyoshi et al. ${ }^{13)}$ proposed a new index, the K-line, which includes preoperative alignment and OPLL size. They reported that K-line (-) was closely associated with a low RR. A recent study reported that laminoplasty was also effective in patients with K-line (-) in the neutral position, but K-line (+) in the extension position ${ }^{40)}$.

The concept of the K-line was originally based on lateral images of the cervical spine. It is difficult to measure, especially for patients with a short neck. Ijima et al. ${ }^{17)}$ pointed out the mismatch between K-line (-/+) in standing lateral images of the cervical spine and supine CT images. Specifically, four of the 33 patients who were measured as K-line (-) on CT images were identified as K-line (+) based on X-rays. Although the clinical results of these mismatched patients were not reported, their findings demonstrate that the K-line cannot be replaced by supine-position images.

Taniyama et al. ${ }^{68,69)}$ developed a modified K-line (mK-line) using T1-weighted sagittal MRI for CSM. Based on the mKline, they measured the minimum interval $\left(\mathrm{INT}_{\min }\right)$ between the mK-line and the anterior compression factor on midsagittal images. In patients with an $\mathrm{INT}_{\text {min }}<4 \mathrm{~mm}$, significant residual anterior compression of the spinal cord (insufficient indirect decompression) may occur, and an $\mathrm{INT}_{\min }<4 \mathrm{~mm}$ is therefore associated with a lower RR than an $\mathrm{INT}_{\min } \geq 4 \mathrm{~mm}$. The findings of Sun et al. ${ }^{66)}$ also support the association of the mK-line with clinical outcomes.

Other variants, such as the kappa line ${ }^{35)}$, K-line tiltt ${ }^{55)}$, coronal $\mathrm{K}$-line, and K-plane ${ }^{37)}$ have been presented at academic meetings, but no clinical articles have investigated their usefulness. 


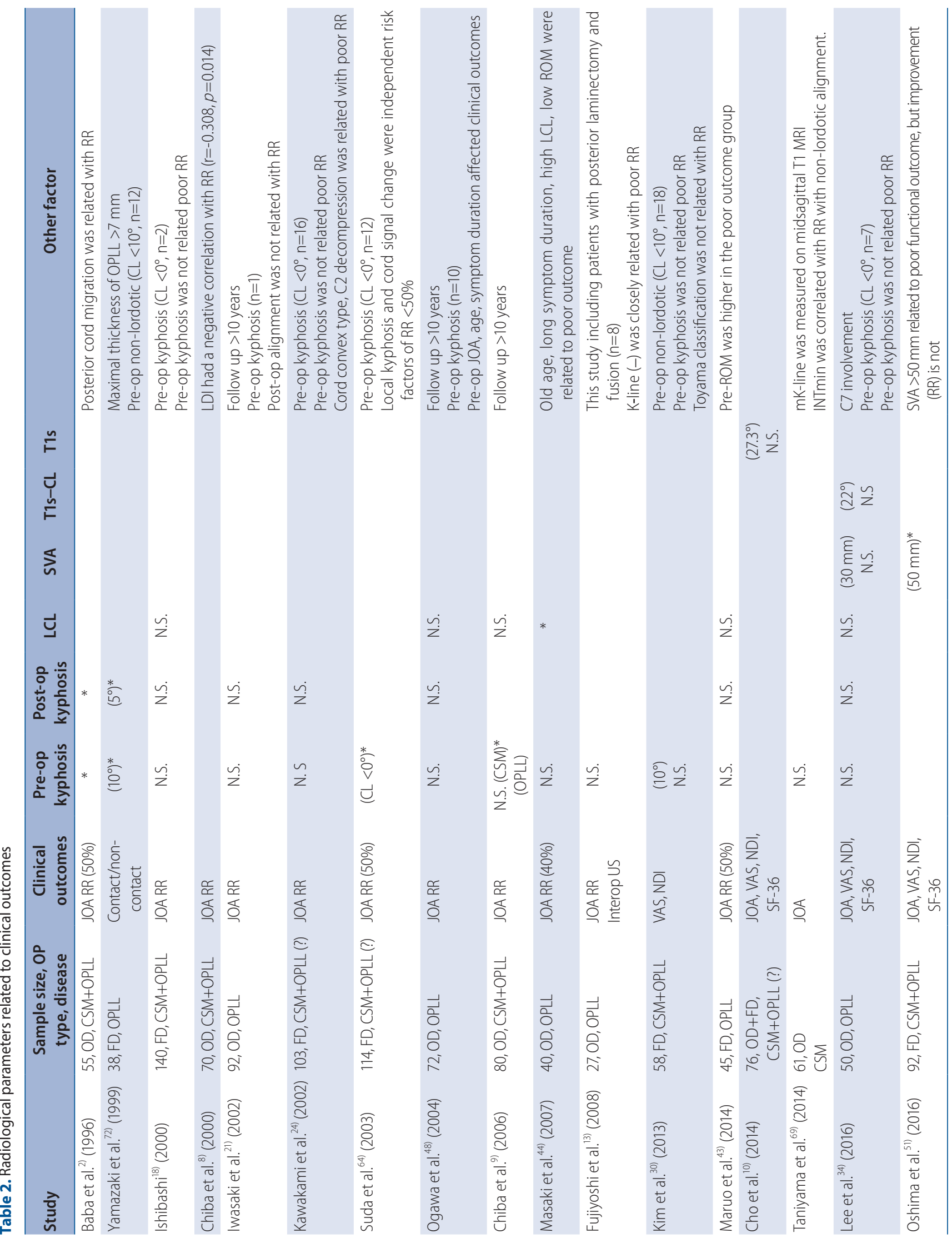




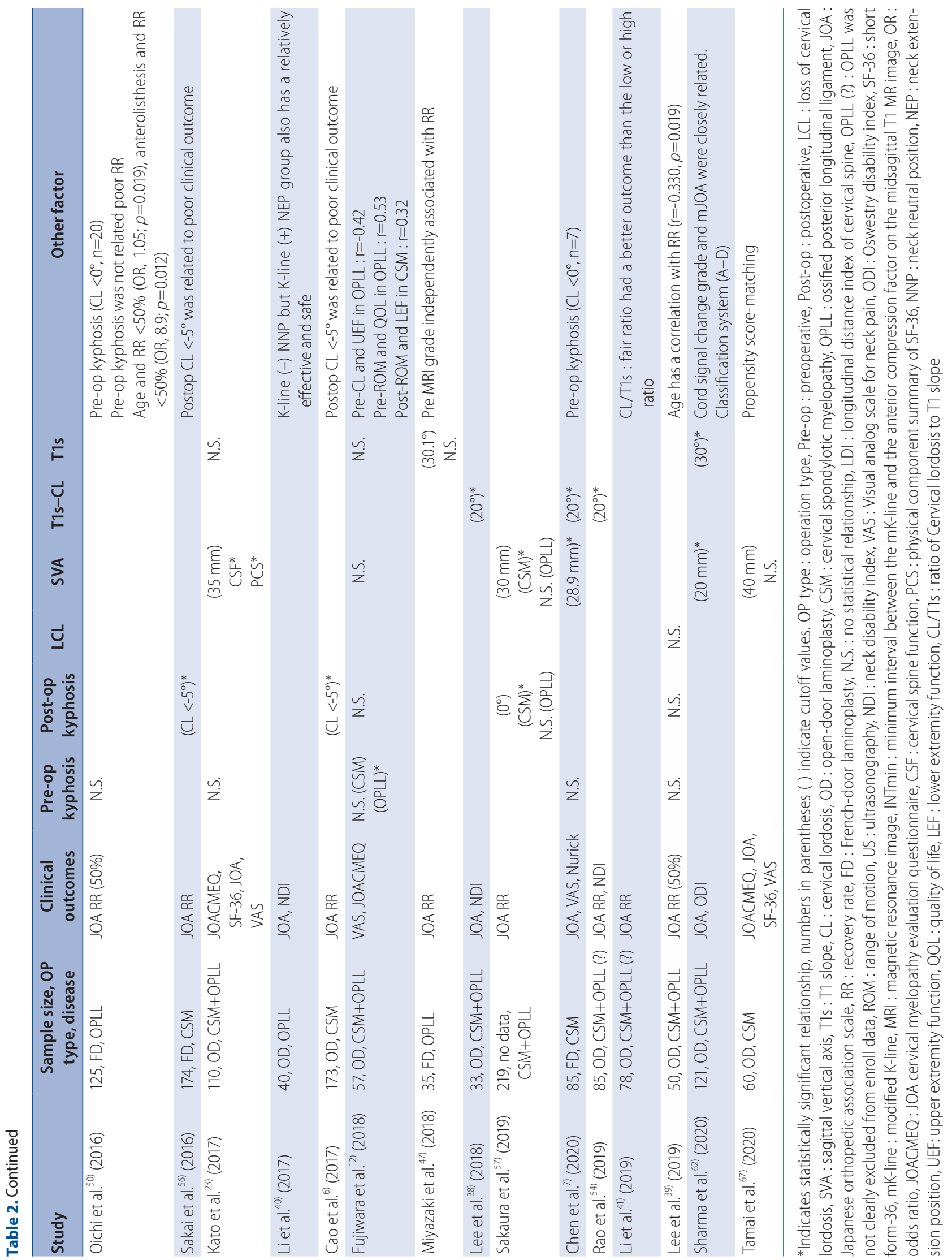


Sagittal balance-related parameters (CSM and OPLL)

Rao et al.$^{54)}$ reported that a mismatch of preoperative T1s and cervical lordosis (CL) of more than $20^{\circ}$ (T1s-CL $\geq 20^{\circ}$ ) was related to poor RR in CSM patients. Sharma et al. ${ }^{62)}$ classified CSM and OPLL patients into four groups using Tls and the sagittal vertical axis (SVA). They reported that the balanced group (T1s $<30^{\circ}$ and SVA $<20 \mathrm{~mm}$ ) had good improvements in the ODI, but the unbalanced group (T1s $\geq 30^{\circ}$ and SVA $\geq 20 \mathrm{~mm}$ ) had poor ODI improvements. Furthermore, various cut-off values of SVA $(28.9,30,35$, and $50 \mathrm{~mm})$ and T1s-CL $\left(20^{\circ}\right)$ have been reported to be related to clinical re-

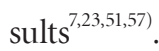

However, Tamai et al. ${ }^{67)}$ performed a propensity scorematching analysis adjusting for age, sex, cervical alignment, and preoperative JOA scores. In an analysis of Japanese Orthopaedic Association Cervical Myelopathy Evaluation Questionnaire responses based on sagittal balance (SVA, $40 \mathrm{~mm}$ ), no statistically significant differences according to balance were found.

\section{T1s (CSM and OPLL)}

Three studies reported no significant relationship between T1s and clinical outcomes. Miyazaki et al. ${ }^{47)}$ found that the MR grade was associated with RR in OPLL patients, but T1s was not. Fujiwara et al. ${ }^{12)}$ also reported no significant relationship between Tls and clinical outcomes in CSM and OPLL patients. Cho et al. ${ }^{10)}$ similarly reported that T1s was not related to VAS, the neck disability index, or the Short form-36.

\section{Range of motion (ROM) (OPLL)}

Maruo et al. ${ }^{43)}$ found that preoperative alignment, LCL, occupying ratio, and MR T2 high signal intensity were not associated with poor outcomes; instead, only preoperative ROM showed an association with poor outcomes. The odds ratio of an $\mathrm{ROM}>20^{\circ}$ for a poor outcome was 4.853 (95\% confidence interval [CI], 1.263-16.635). Masaki et al. ${ }^{44)}$ also reported that larger preoperative and postoperative ROMs were related to poor outcomes.

Radiological change (LCL, post-operative kyphosis) (CSM and OPLL)

Controversy exists regarding whether these two factors are of clinical significance. Sakaura et al. ${ }^{57)}$ found that the RR was lower in CSM patients with postoperative kyphosis. This rela- tionship was not found in OPLL patients. Sharma et al. reported that an LCL $>10^{\circ}$ was related to lower ODI changes ${ }^{62)}$. Masaki et al. ${ }^{44)}$ also reported that greater LCL was associated with poor outcomes. However, other studies have reported that LCL or postoperative kyphosis did not affect clinical outcomes $^{34,43,47)}$.

\section{Miscellaneous}

Anterolisthesis (CSM) was a significant risk factor for poor outcome ( $p=0.01$ ), whereas retrolisthesis did not affect the neurological outcomes $(p=0.6)^{50)}$. Local kyphosis (CSM) was related with poor outcome (RR <50\%) (odds ratio [OR], 6.69 per $10^{\circ}$ kyphosis; $\left.p<0.01\right)^{64)}$. Longitudinal distance index (LDI) of cervical spine (CSM and OPLL) was significantly lower in the CSM group than in the OPLL group. Also, LDI had a weak but statistically significant negative correlation with $\mathrm{RR}(\mathrm{r}=$ $-0.308, p=0.014)^{8)}$.

\section{Preoperative radiological parameters predicting radiological outcomes}

\section{$\mathrm{LCL}$}

Pre-operative T1s, SVA, CL, ROM, T1s-CL, the ratio of CL to T1s (CL/T1s) and extension function (EF) have been proposed as risk factors for LCL. Table 3 summarizes the relationships of LCL with those proposed factors.

T1s : Kim et al. ${ }^{31)}$ first reported that high/low T1s were related to LCL in CSM. On the contrary, Cho et al. ${ }^{10)}$ reported no relationship between T1s and LCL. Subsequently, studies reporting positive or negative findings regarding this relationship have been published ${ }^{10,38,39)}$. Even in papers supporting the existence of a relationship between T1s and LCL, the correlation coefficient ( $\mathrm{r}$ ) was low, near $0.3^{27,33,36,47,56,74)}$.

EF : This parameter represents the contraction reserve of the posterior musculo-ligament complex. This factor was found explained the phenomenon of low LCL in patients with a high T1s. Lee et al. ${ }^{39)}$ reported that the correlation coefficient (r) between EF and LCL was 0.504, which had a stronger correlation than that found for T1s. This parameter is also included in the Sharma classification ${ }^{62}$.

Ratio of CL to T1s (CL/T1s) : Li et al. ${ }^{41)}$ classified the CL/T1s ratio as low (bottom 25\%; CL/T1s $<0.45$ ), fair (middle 50\%; $\mathrm{CL} / \mathrm{T} 1 \mathrm{~s}$ ranging from 0.45 to 1.05 ), or high (top $25 \%$; CL/T1s $>1.05)$. A high $\mathrm{CL} / \mathrm{T} 1 \mathrm{~s}$ ratio was significantly related to a high 


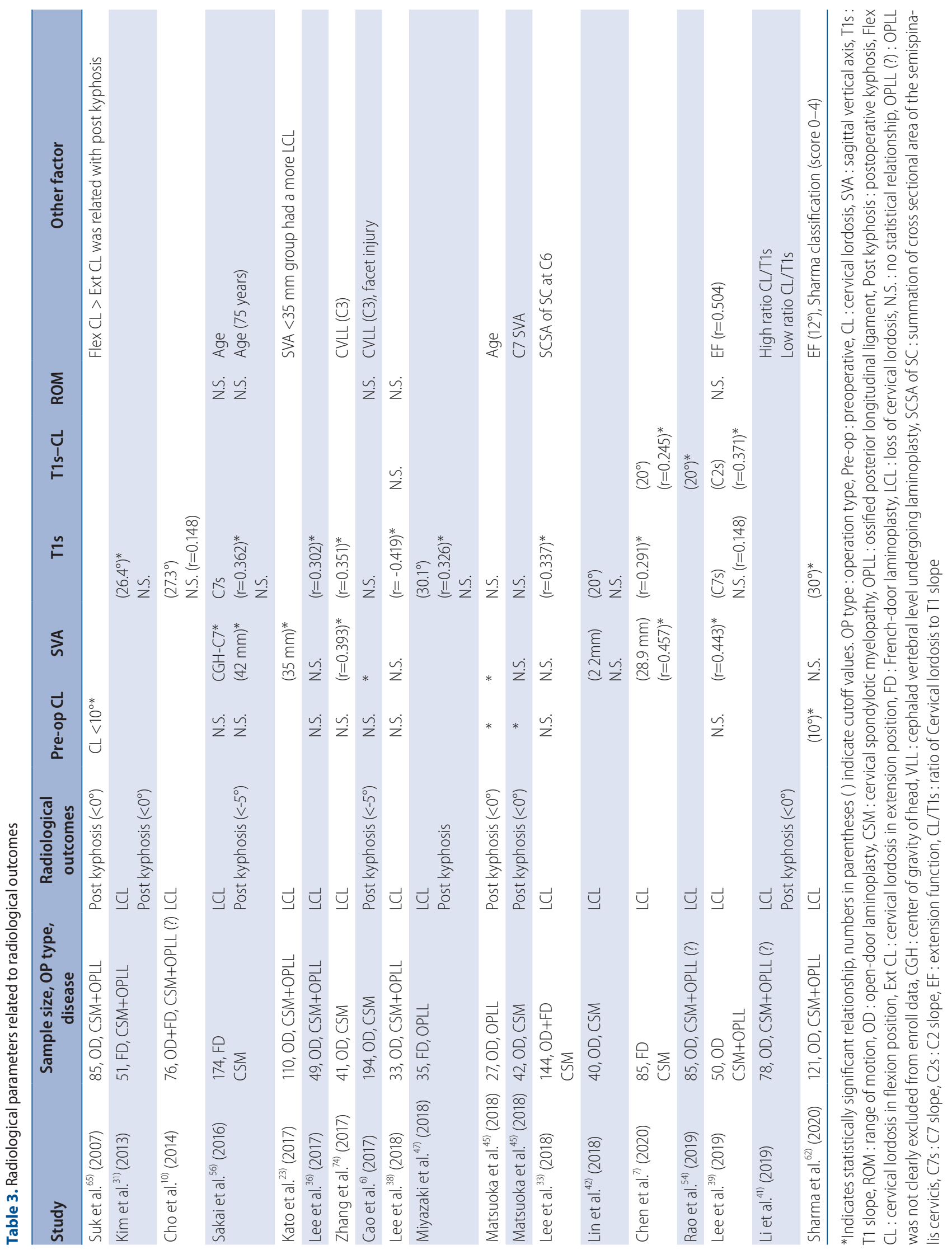


LCL (high ratio, $14.53 \pm 0.63$; fair ratio, 5.51 \pm 7.59 ; low ratio, $0.95 \pm 9.84 ; p<0.001)$.

Sharma classification : The Sharma classification presents a scoring system including preoperative $\mathrm{CL}, \mathrm{T} 1 \mathrm{~s}$, and $\mathrm{EF}^{62)}$. Of particular note, it separately presents straight curvature (Cobb angle $[\mathrm{CA}]<10^{\circ}$ ), which can frequently occur in patients with postoperative kyphosis due to LCL. In the score 0 group (CA $<10^{\circ}$, T1s $<30^{\circ}, \mathrm{EF}>12^{\circ}$ ), significant LCL $\left(>10^{\circ}\right)$ occurred in $0 \%$ of patients. In contrast, $100 \%$ of patients with a score of 4 $\left(\mathrm{CA}>10^{\circ}, \mathrm{T} 1 \mathrm{~s}>30^{\circ}, \mathrm{EF}<12^{\circ}\right)$ had significant LCL.

\section{Postoperative kyphosis}

Postoperative kyphosis is a distinct concept from LCL. In postoperative kyphosis, LCL occurs on the basis of preoperative $\mathrm{CL}$, and as a result, the postoperative $\mathrm{CL}$ is $<-10^{\circ}$.

Preoperative $\mathrm{CL}<10^{\circ}$ : Patients with preoperative $\mathrm{CL}<10^{\circ}$ can easily develop postoperative kyphosis, even with a slight LCL. Suk et al. ${ }^{65)}$ reported that patients with preoperative CL $<10^{\circ}$ had more postoperative kyphosis than those with preoperative $\mathrm{CL}>10^{\circ}$ (OR, 7.625; $\left.p=0.008\right)$.

Kyphotic angle in flexion position $>$ lordotic angle in extension position : This pattern was related to postoperative kyphosis (OR, 9.167; $p=0.005)^{65)}$.

T1s : Three studies analyzed the association between high/ low T1s and postoperative kyphosis, but found no significant association between the two factors ${ }^{27,31,47)}$.
CL/T1s : Patients with a low CL/T1s ratio had a significantly higher rate of postoperative kyphosis than those with a fair or high ratio (OR, 16.63; 95\% CI, 3.07-90.12; $p<0.001)^{41)}$.

\section{Case presentation}

We categorized the preoperative alignment parameter for which laminoplasty is relatively preferred or not through a review of the previous literature (Fig. 3). In patients with straight or lordotic curves, LCL prediction is important. If the risk of LCL is low, sufficient decompression can be expected (case 1), but if the risk of LCL is high, postoperative alignment could be changed to kyphotic alignment (CSM) or K-line (-) (OPLL) (case 4). These changes closely related to insufficient decompression, leading to a poor clinical outcome. In the case of kyphotic alignment, laminoplasty corresponds to relative contraindication (case 3). However, as reported in the previous literature, some patients recovered to lordosis after surgery, and have shown a relatively good clinical course ${ }^{9,21,48)}$. There is no known mechanism about the recovery of kyphotic alignment to the lordotic curve after surgery, but we should note that patients with kyphotic alignment could be compensatory alignment due to pain limitation (case 2). The extension position helps to differentiate these compensatory alignments. This differentiation can help determine whether to perform laminoplasty in kyphotic alignment patient group with a high risk of complications from the fusion operation, such as elder-

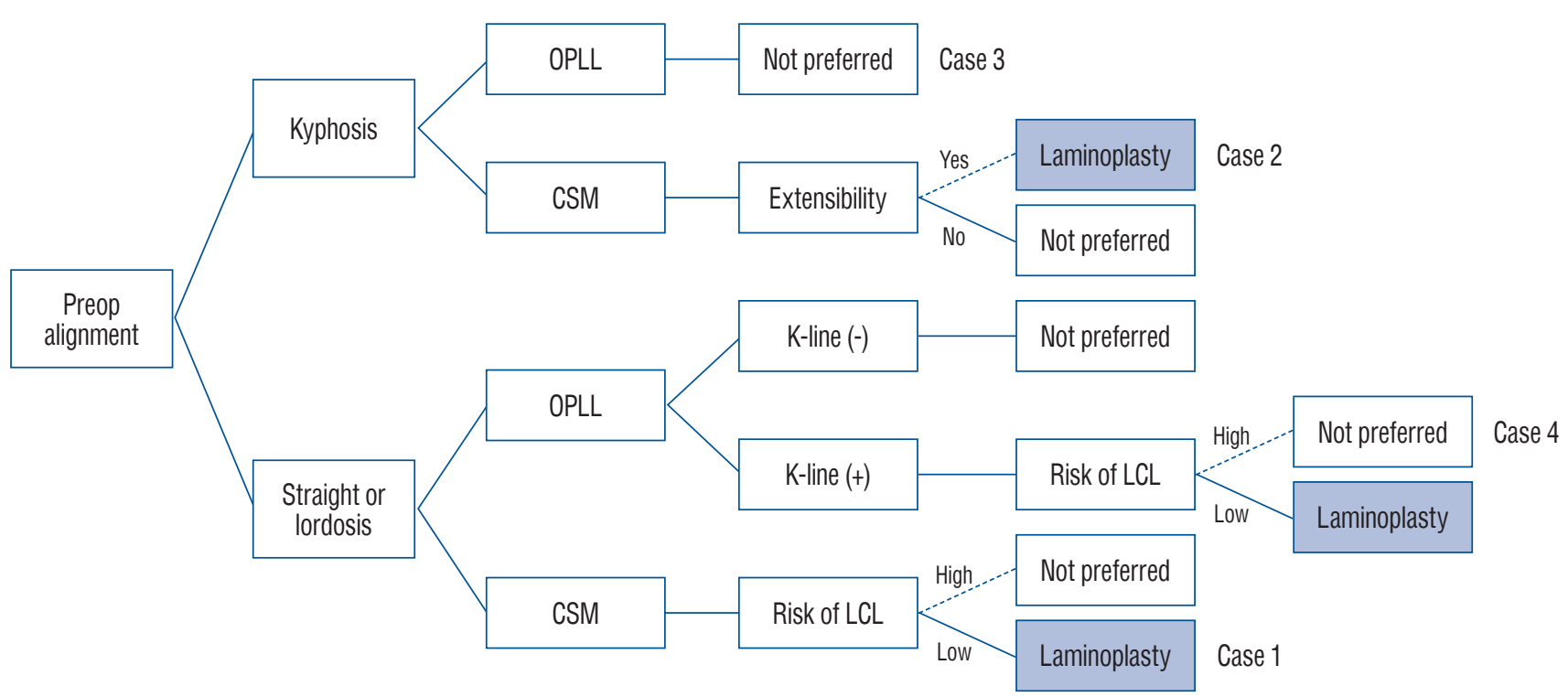

Fig. 3. Schema of the indication of laminoplasty according to preoperative alignment, diagnosis, K-line, and loss of cervical lordosis. Preop : preoperative, OPLL : ossified posterior longitudinal ligament, CSM : cervical spondylotic myelopathy, LCL : loss of cervical lordosis. 
ly and severe osteoporosis.

\section{Case 1 (Fig. 4)}

A 55-year-old male patient with preoperative straight curve had severe preoperative neck pain (VAS, 7), and gait disturbance (pre-operative mJOA, 15). Preoperative CA was 5.7 ${ }^{\circ}$, T1s was $26.4^{\circ}$, and EF was $12.1^{\circ}$. This corresponds to 'Ia' type and score 0 in Sharma classification and the probability of LCL was reported as $0 \%$. Postoperative CA was $12.4^{\circ}$ and no LCL occurred. After surgery, neck pain was decreased (VAS, 4), and $\mathrm{mJOA}$ recovered to 18 ( $\mathrm{RR}, 100 \%)$. On postoperative MRI, we found that the spinal cord was freed from the anterior lesion by indirect decompression following sufficient posterior shifting after laminoplasty.

\section{Case 2 (Fig. 5)}

A 66-year-old male patient had a preoperative kyphotic alignment (preoperative CA, $-15.9^{\circ}$; T1s, $15.2^{\circ}$; EF, 25.60 ${ }^{\circ}$ ). The patient had severe preoperative arm pain (VAS, 8) and complained of a decrease in hand fine motor and gait disturbance (preoperative mJOA, 12). Although kyphotic alignment was not applied to Sharma classification, both T1s and EF were low-risk factors for LCL. The patient recovered to straight curvature (postoperative CA, $0.9^{\circ}$ ) after surgery. The neck pain did not improve, but the arm pain improved. (VAS, 3), and $\mathrm{m}$ JOA recovered to $16(\mathrm{RR}, 66.7 \%)$.

\section{Case 3 (Figs. 5 and 6)}

A 52-year-old male patient was diagnosed with C2-6 continuous type OPLL. The patient complained of severe neck pain and arm pain (both VAS, 8), deterioration of the hand fine motor and gait disturbance (preoperative mJOA, 10). The patient had a preoperative kyphotic alignment (preoperative CA, $-11.4^{\circ}$ ), and the EF was also limited to $7.1^{\circ}$. There was no significant change in alignment after surgery (postoperative CA, $-9^{\circ}$ ) and T1s was decreased for compensation (preoperative, $16.7^{\circ}$; postoperative, $12.5^{\circ}$ ). Neck and arm pain partially decreased (neck VAS, 6; arm VAS, 4), but there was no significant improvement in hand fine motor and gait (mJOA, 13; RR, 37.50\%). On postoperative MRI, the spinal canal was widened after laminoplasty, but the cord was still compressed by the anterior lesion.
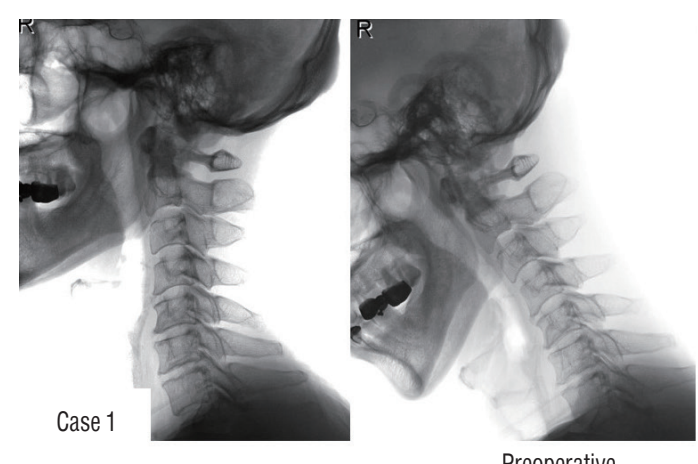

Preoperative

CL 5.7, SVA 22.16, T1s 26.4, Flex CL -24.5, Ext CL 17.8

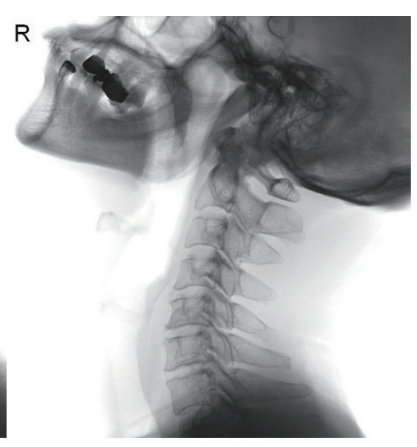

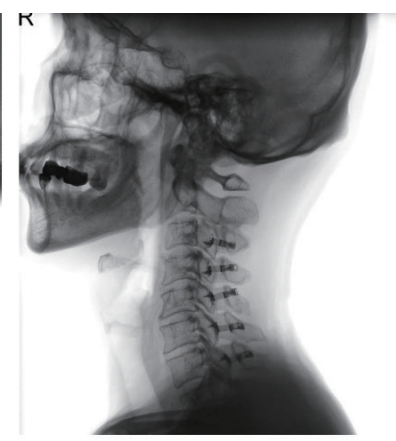

Postoperative CL 12.4, SVA 11.15, T1s 23.1

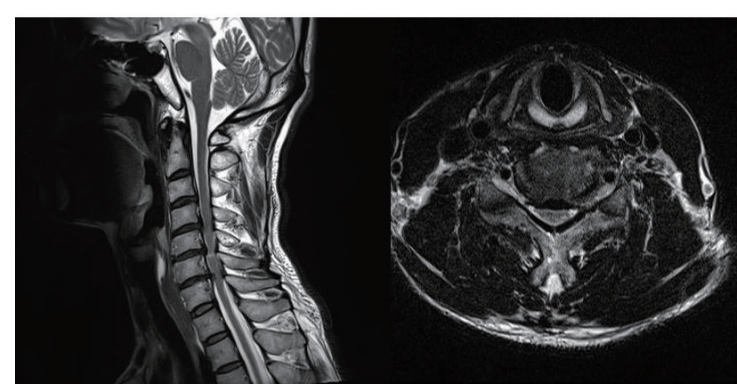

Preoperative

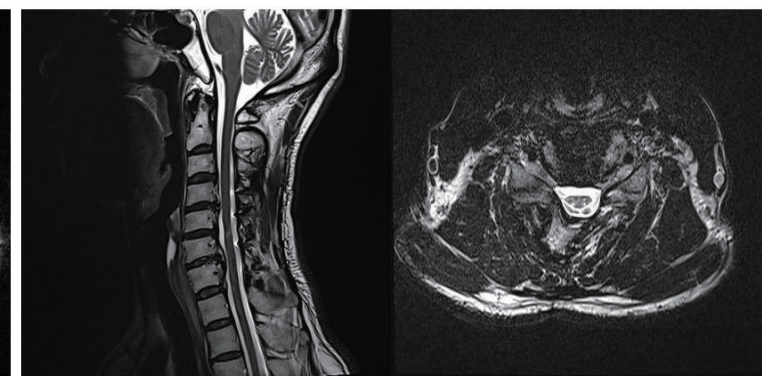

Postoperative

Fig. 4. Sufficient indirect decompression (case 1). CL : cervical lordosis, SVA : sagittal vertical axis, $\mathrm{T} 1 \mathrm{~s}$ : $\mathrm{T} 1$ slope, Flex $\mathrm{CL}$ : cervical lordosis in flexion position, Ext $\mathrm{CL}$ : cervical lordosis in extension position. 

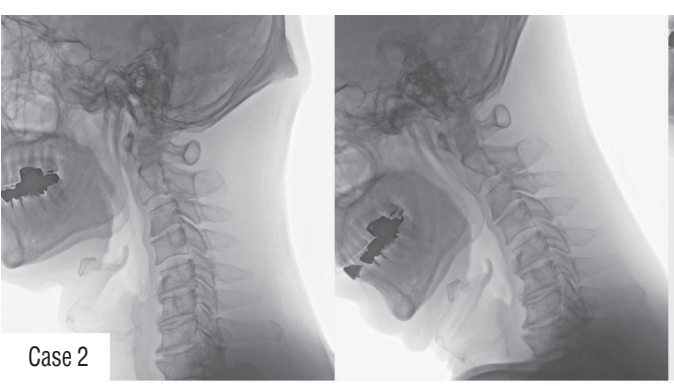

Preoperative

CL -15.9, SVA 28.77, T1s 15.2, Flex CL -27.8, Ext CL 9.7, EF 25.60
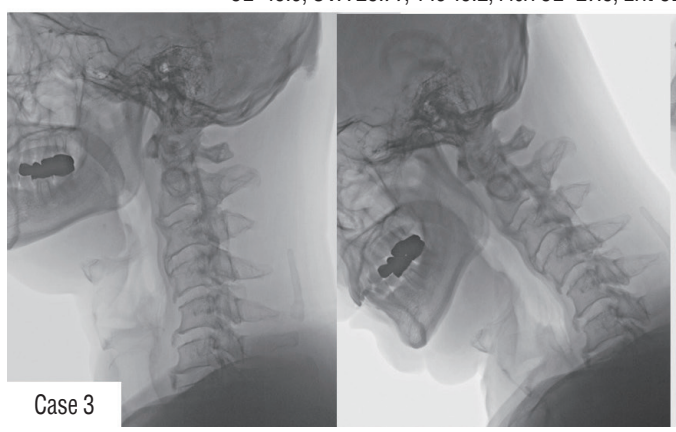

Preoperative

CL -11.4, SVA 25.16, T1s 16.7, Flex CL -31.1, Ext CL -4.3, EF 7.1

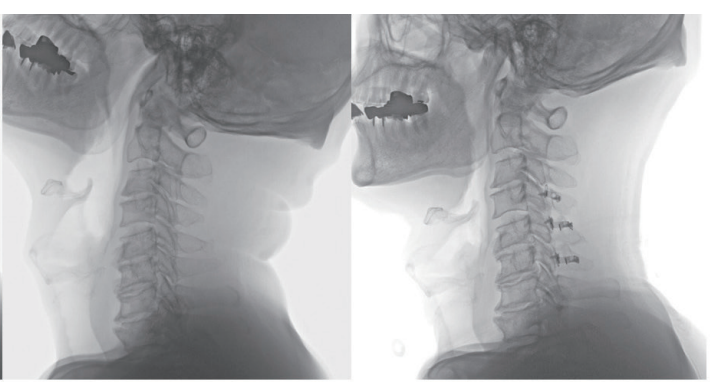

Postoperative

CL 0.9, SVA 18.63, T1s 16.1
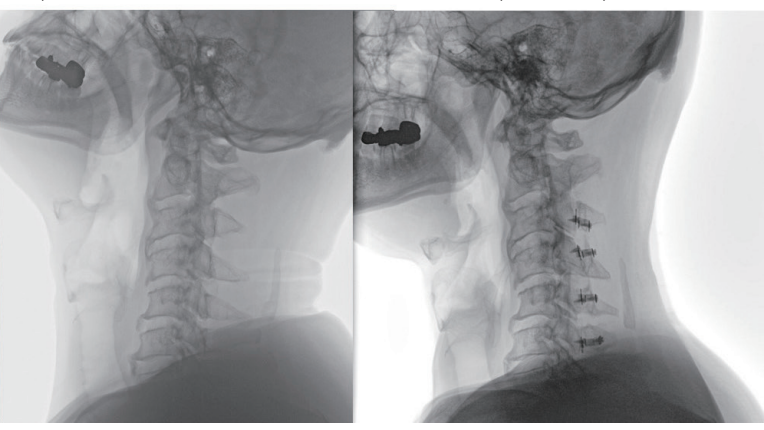

Postoperative
CL -9.0, SVA 18.88, T1s 12.5

Fig. 5. Different postoperative alignment and clinical outcomes in two patients with preoperative kyphotic alignment (case 2 [upper] and case 3 [lower]). CL : cervical lordosis, SVA : sagittal vertical axis, T1s: T1 slope, Flex CL : cervical lordosis in flexion position, Ext CL : cervical lordosis in extension position, $\mathrm{EF}$ : extension function.

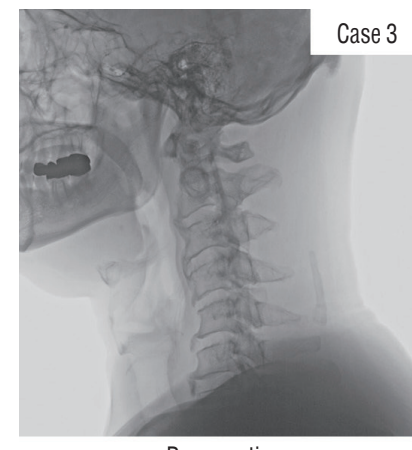

Preoperative

CL -11.4, SVA 25.16, T1s 16.7

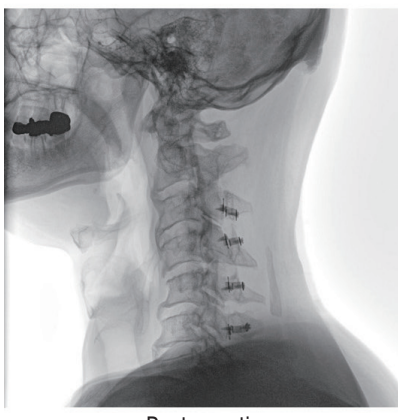

Postoperative

CL -9.0 , SVA 18.88 , T1s 12.5

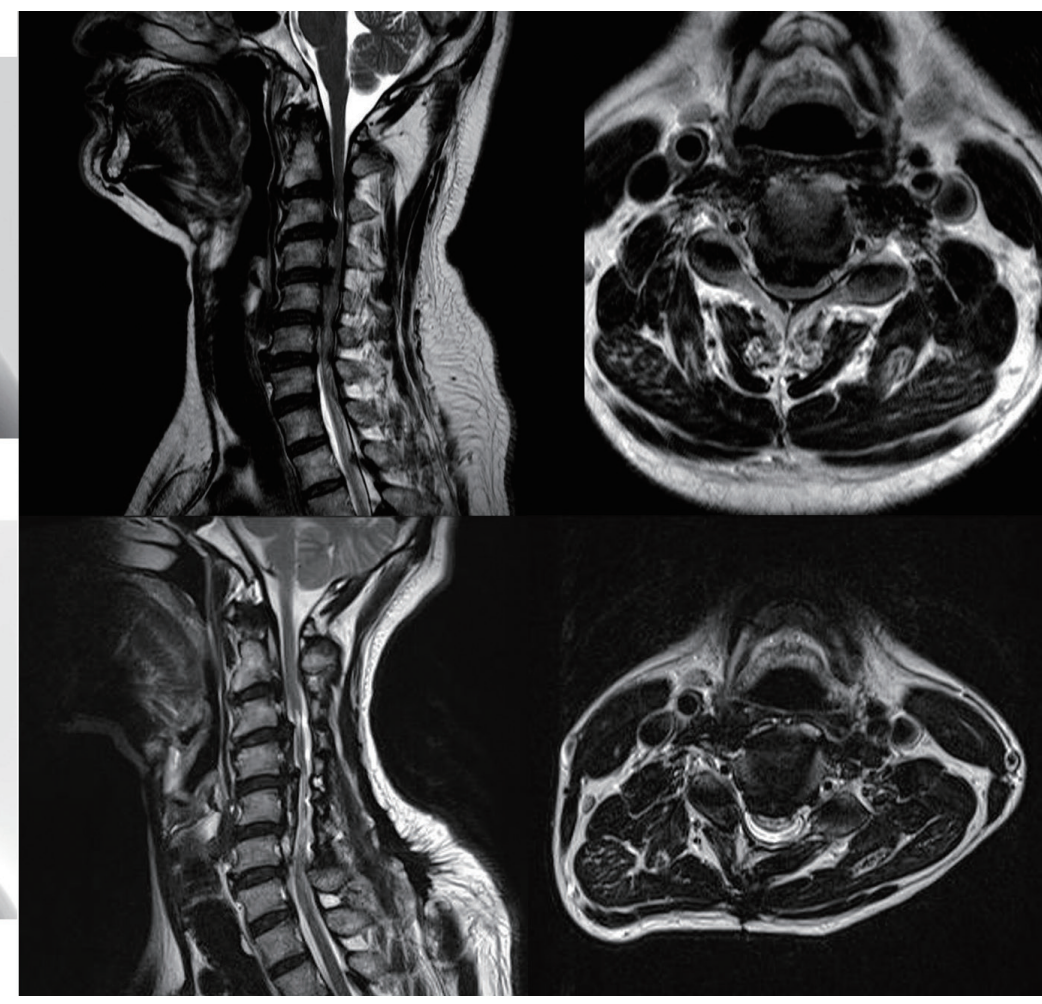

Fig. 6. Failure of indirect decompression in patients with preoperative kyphotic alignment (case 3). CL : cervical lordosis, SVA : sagittal vertical axis, T1s : T1 slope. 

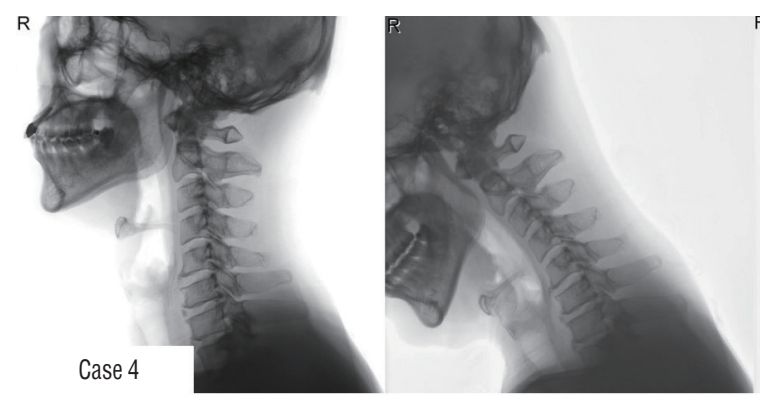

Preoperative

CL -1.4, SVA 24.31, T1s 18, Flex CL -35.6, Ext CL 9.2, EF 10.6
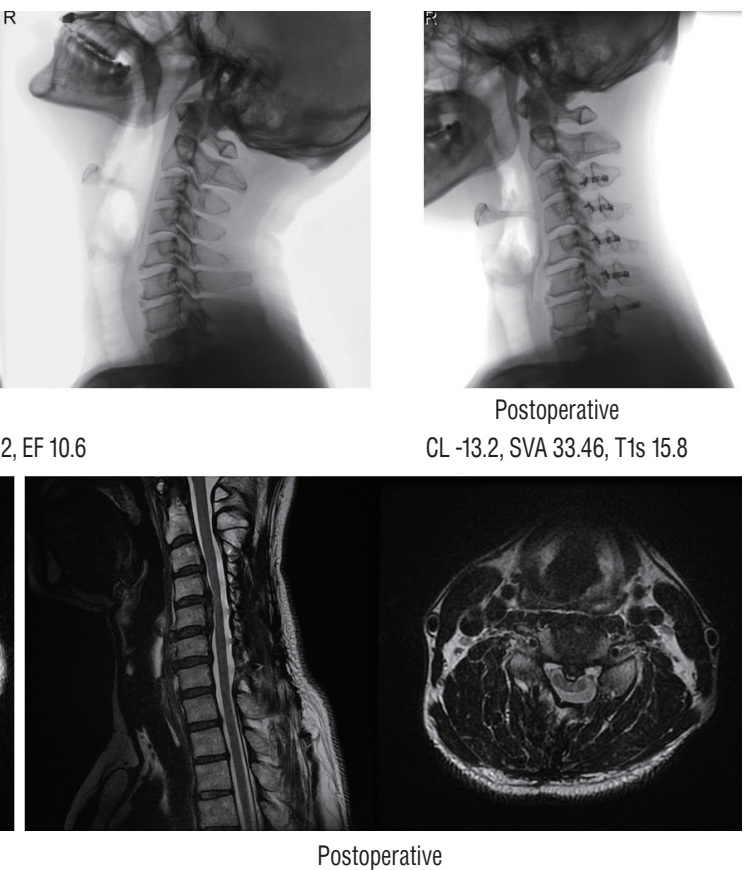

Fig. 7. Failure of indirect decompression following loss of cervical lordosis in preoperative straight alignment patients (case 4). CL : cervical lordosis, SVA : sagittal vertical axis, T1s: T1 slope, Flex CL : cervical lordosis in flexion position, Ext CL : cervical lordosis in extension position, $\mathrm{EF}$ : extension function.

\section{Case 4 (Fig. 7)}

A 52-year-old male patient with segmental OPLL complained of severe arm pain (VAS, 7) and fine hand motor weakness (mJOA, 15). The patient had a preoperative straight alignment (preoperative CA, $-1.4^{\circ}$ ), Preoperative T1s was $18.0^{\circ}$, and $\mathrm{EF}$ was $10.6^{\circ}$. This corresponds to 'Ib' type and score 1 in Sharma classification, and the probability of LCL was reported as $20 \%$. There was $11.8^{\circ}$ of LCL, and kyphotic alignment was obtained after surgery (postoperative CA, $-13.2^{\circ}$ ). We found the insufficient indirect decompression in postoperative MRI. There was some improvement in arm pain after surgery (VAS, 4), but there was no significant improvement in fine motor weakness (mJOA, 16; RR, 33.3\%).

\section{DISCUSSION}

The World Federation of Neurosurgical Societies (WFNS) spine committee recently announced recommendations for CSM and OPLL ${ }^{3,11,53,75-77)}$. The WFNS recommendations pointed out that the most important factors associated with the clinical results of CSM are age, symptom duration, and disease severity. However, because these factors are non-mod- ifiable, numerous studies have attempted to find modifiable factors that influence clinical outcomes. The most important modifiable factor related to clinical results is the surgical approach $^{14,52)}$. Among the several surgical approaches, laminoplasty is preferred because it has fewer complications than anterior corpectomy and fusion or posterior laminectomy and fusion, especially in older osteoporotic patients $s^{3,14,28,40,71)}$. The current consensus is that laminoplasty is indicated in patients with neutral or lordotic alignment without significant axial pain and in K-line (+) OPLL patients. However, these indications do not always lead to good clinical outcomes. This review conducted a literature review of all possible pre-operative radiological parameters on why poor clinical/radiological outcomes occur in some of the patients even corresponding to the indication.

Most studies investigating the effect of preoperative alignment on clinical outcomes did not report statistical significance (Table 2). The clinical results are primarily affected by age, disease severity, and symptom duration. Additionally, MR-based parameters, such as the occupying ratio, OPLL shape, and cord signal change have a significant impact on clinical outcomes. Complications of laminoplasty such as LCL, C5 palsy ${ }^{49)}$, postoperative neck pain, increased size of 
OPLL $^{70)}$, decreased ROM, and insufficient decompression also affects clinical outcomes. In this regard, there is a limited degree to which clinical effects can be analyzed in terms of alignment factors alone. Various factors are involved in predicting clinical outcomes, and further research using recent big data technology (e.g., deep learning) is needed for a comprehensive analysis $^{22,26,29,59)}$.

Patients with alignments suitable for laminoplasty can proceed with postoperative kyphotic alignment or postoperative K-line (-) according to LCL. In this regard, LCL has been actively studied, but the exact mechanism has not been established. Many studies have investigated the role of T1s in LCL, but the reported correlation coefficients are low (near 0.3), and some studies have also reported no correlation (Table 3). A meta-analysis is needed to resolve this controversy. Recognition of the limitations of T1s as an LCL predictor led to the study of new risk factors, such as EF, CL/T1s, Sharma classification. EF is a recently proposed factor that showed a higher correlation coefficient than existing factors ${ }^{39}$. The correlation between LCL and EF was also confirmed by Sharma et al. ${ }^{62}$. Li et al. ${ }^{41)}$ reported more LCL was related to high CL/T1s, and postoperative kyphosis was related to low CL/T1s. The Sharma classification has shown an excellent prediction rate of significant LCL. However, reproducibility studies in other groups have not yet been conducted, and the Sharma classification does not reflect differences among disease entities, such as CSM and OPLL.

This study has the following limitations. First, this study was aimed at systematic review, but nine additional papers were identified in the reference during the searching process $(9 / 41,22 \%)$. The influx of these additional papers can act as a limit to securing objectivity as a systematic review. The second, we did not perform meta-analysis related to outcomes. This study focuses on the identification of various factors. In that respect, many factors have been suggested, and various clinical or radiological factors have been suggested as dependent factors. In that respect, there was a limit to performing a meta-analysis.

\section{CONCLUSION}

Numerous sagittal parameters are associated with clinical and radiological outcomes after laminoplasty. We classified the suggested sagittal parameters into clinical and radiological results and summarized the previous literature. Pre-operative kyphotic alignment, K-line, and pre-operative sagittal balance were considered important factors in the prediction of clinical results. In addition, we should pay attention to the occurrence of postoperative kyphotic alignment according to LCL even without preoperative kyphotic alignment. With regard to LCL, T1s has been suggested as an important risk factor. However, due to the weak correlation between T1s and LCL, new factors, such as EF, CL/T1s, and Sharma classification, have been proposed, and validation of these factors is required.

\section{CONFLICTS OF INTEREST}

Dong Wuk Son has been editorial board of JKNS since November 2017. He was not involved in the review process of this original article. No potential conf lict of interest relevant to this article was reported.

\section{INFORMED CONSENT}

This type of study does not require informed consent.

\section{AUTHOR CONTRIBUTIONS}

\author{
Conceptualization : DWS, JJS, YH, GSS \\ Data curation : SHL, DWS, JJS, JSL \\ Formal analysis : SHL, DWS, JSL \\ Funding acquisition : SHL, DWS, JSL, GSS \\ Methodology: SHL, DWS, JJS, YH, GSS, SWL \\ Project administration: SHL, DWS, JJS, YH, GSS, JSL, \\ SWL \\ Visualization : SHL, DWS, JJS, JSL \\ Writing - original draft : SHL, DWS, JJS, YH, GSS, JSL, \\ SWL \\ Writing - review \& editing : SHL, DWS, JJS, YH, GSS, JSL, \\ SWL
}




\section{ORCID}

$\begin{array}{ll}\text { Su Hun Lee } & \text { https://orcid.org/0000-0001-8952-5556 } \\ \text { Dong Wuk Son } & \text { https://orcid.org/0000-0002-9154-1923 } \\ \text { Jun Jae Shin } & \text { https://orcid.org/0000-0002-1503-6343 } \\ \text { Yoon Ha } & \text { https://orcid.org/0000-0002-3775-2324 } \\ \text { Geun Sung Song } & \text { https://orcid.org/0000-0002-8273-7596 } \\ \text { Jun Seok Lee } & \text { https://orcid.org/0000-0003-2488-6953 } \\ \text { Sang Weon Lee } & \text { https://orcid.org/0000-0002-3199-7072 }\end{array}$

\section{- Acknowledgements}

This study was supported by Research institute for Convergence of biomedical science and technology (30-2018-020), Pusan National University Yangsan Hospital.

\section{References}

1. Aita I, Wadano Y, Yabuki $\mathrm{T}$ : Curvature and range of motion of the cervical spine after laminaplasty. J Bone Joint Surg Am 82 : 1743-1748, 2000

2. Baba H, Uchida K, Maezawa Y, Furusawa N, Azuchi M, Imura S : Lordotic alignment and posterior migration of the spinal cord following en bloc open-door laminoplasty for cervical myelopathy: a magnetic resonance imaging study. J Neurol 243 : 626-632, 1996

3. Bajamal AH, Kim SH, Arifianto MR, Faris M, Subagio EA, Roitberg $B$, et al. : Posterior surgical techniques for cervical spondylotic myelopathy: WFNS Spine Committee recommendations. Neurospine 16 : 421-434, 2019

4. Batzdorf $U$, Batzdorff $A$ : Analysis of cervical spine curvature in patients with cervical spondylosis. Neurosurgery 22 : 827-836, 1988

5. Batzdorf U, Flannigan BD : Surgical decompressive procedures for cervical spondylotic myelopathy. A study using magnetic resonance imaging. Spine (Phila Pa 1976) 16 : 123-127, 1991

6. Cao J, Zhang J, Yang D, Yang L, Shen Y : Multivariate analysis of factors associated with kyphotic deformity after laminoplasty in cervical spondylotic myelopathy patients without preoperative kyphotic alignment. Sci Rep 7 : 43443, 2017

7. Chen HY, Yang MH, Lin YP, Lin FH, Chen PQ, Hu MH, et al. : Impact of cervical sagittal parameters and spinal cord morphology in cervical spondylotic myelopathy status post spinous process-splitting laminoplasty. Eur Spine J 29 : 1052-1060, 2020

8. Chiba K, Toyama Y, Watanabe M, Maruiwa H, Matsumoto M, Hirabayashi $\mathrm{K}$ : Impact of longitudinal distance of the cervical spine on the results of expansive open-door laminoplasty. Spine (Phila Pa 1976) $25: 2893-2898,2000$

9. Chiba K, Ogawa Y, Ishii K, Takaishi H, Nakamura M, Maruiwa H, et al. :
Long-term results of expansive open-door laminoplasty for cervical myelopathy--average 14-year follow-up study. Spine (Phila Pa 1976) 31 : 2998-3005, 2006

10. Cho JH, Ha JK, Kim DG, Song KY, Kim YT, Hwang CJ, et al. : Does preoperative T1 slope affect radiological and functional outcomes after cervical laminoplasty? Spine (Phila Pa 1976) 39 : E1575-E1581, 2014

11. Deora H, Kim SH, Behari S, Rudrappa S, Rajshekhar V, Zileli M, et al. : Anterior surgical techniques for cervical spondylotic myelopathy: WFNS Spine Committee recommendations. Neurospine 16 : 408-420, 2019

12. Fujiwara H, Oda T, Makino T, Moriguchi Y, Yonenobu K, Kaito T : Impact of cervical sagittal alignment on axial neck pain and health-related quality of life after cervical laminoplasty in patients with cervical spondylotic myelopathy or ossification of the posterior longitudinal ligament: a prospective comparative study. Clin Spine Surg 31 : E245-E251, 2018

13. Fujiyoshi T, Yamazaki M, Kawabe J, Endo T, Furuya T, Koda M, et al. : A new concept for making decisions regarding the surgical approach for cervical ossification of the posterior longitudinal ligament: the K-line. Spine (Phila Pa 1976) 33 : E990-E993, 2008

14. Head J, Rymarczuk G, Stricsek G, Velagapudi L, Maulucci C, Hoelscher $C$, et al. : Ossification of the posterior longitudinal ligament: surgical approaches and associated complications. Neurospine 16 : 517-529, 2019

15. Hirabayashi K, Miyakawa J, Satomi K, Maruyama T, Wakano K : Operative results and postoperative progression of ossification among patients with ossification of cervical posterior longitudinal ligament. Spine (Phila Pa 1976) 6 : 354-364, 1981

16. Hirabayashi $K$, Watanabe $K: A$ review of my invention of expansive laminoplasty. Neurospine $16:$ 379-382, 2019

17. Ijima Y, Furuya T, Ota M, Maki S, Saito J, Kitamura M, et al. : The K-line in the cervical ossification of the posterior longitudinal ligament is different on plain radiographs and CT images. J Spine Surg 4 : 403-407, 2018

18. Ishibashi $\mathrm{K}$ : Expansive laminoplasty by sagittal splitting of the spinous process for cervical myelopathy: correlation of clinical results with morphological changes in the cervical spine. Kurume Med J 47 : 135-145, 2000

19. Ito K, Yukawa $Y$, Ito K, Machino M, Kanbara S, Nakashima H, et al. : Dynamic changes in the spinal cord cross-sectional area in patients with myelopathy due to cervical ossification of posterior longitudinal ligament. Spine J 15 : 461-466, 2015

20. Itoki K, Kurokawa R, Shingo T, Kim P : Effect of myoarchitectonic spinolaminoplasty on concurrent hypertension in patients with cervical spondylotic myelopathy. Neurospine $15:$ 77-85, 2018

21. Iwasaki M, Kawaguchi $Y$, Kimura $T$, Yonenobu $\mathrm{K}$ : Long-term results of expansive laminoplasty for ossification of the posterior longitudinal ligament of the cervical spine: more than 10 years follow up. J Neurosurg 96(2 Suppl) : 180-189, 2002

22. Joshi RS, Haddad $A F$, Lau $D$, Ames $C P$ : Artificial intelligence for adult spinal deformity. Neurospine 16 : 686-694, 2019

23. Kato M, Namikawa T, Matsumura A, Konishi S, Nakamura H : Effect of cervical sagittal balance on laminoplasty in patients with cervical my- 
elopathy. Global Spine J 7 : 154-161, 2017

24. Kawakami M, Tamaki T, Ando M, Yamada H, Yoshida M : Relationships between sagittal alignment of the cervical spine and morphology of the spinal cord and clinical outcomes in patients with cervical spondylotic myelopathy treated with expansive laminoplasty. J Spinal Disord Tech $15: 391-397,2002$

25. Kawanabe Y, Fujimoto M, Sato T : Cervical open-door laminoplasty by hydroxyapatite implant insertion without suturing. Neurospine 15 : 362-367, 2018

26. Khan O, Badhiwala JH, Wilson JRF, Jiang F, Martin AR, Fehlings MG : Predictive modeling of outcomes after traumatic and nontraumatic spinal cord injury using machine learning: review of current progress and future directions. Neurospine 16 : 678-685, 2019

27. Kim B, Yoon DH, Ha Y, Yi S, Shin DA, Lee CK, et al. : Relationship between $\mathrm{T} 1$ slope and loss of lordosis after laminoplasty in patients with cervical ossification of the posterior longitudinal ligament. Spine J 16 : 219-225, 2016

28. Kim DH, Lee CH, Ko YS, Yang SH, Kim CH, Park SB, et al. : The clinical implications and complications of anterior versus posterior surgery for multilevel cervical ossification of the posterior longitudinal ligament; an updated systematic review and meta-analysis. Neurospine 16 : 530541, 2019

29. Kim M, Yun J, Cho Y, Shin K, Jang R, Bae HJ, et al. : Deep learning in medical imaging. Neurospine 16 : 657-668, 2019

30. Kim SW, Hai DM, Sundaram S, Kim YC, Park MS, Paik SH, et al. : Is cervical lordosis relevant in laminoplasty? Spine J 13 : 914-921, 2013

31. Kim TH, Lee SY, Kim YC, Park MS, Kim SW : T1 slope as a predictor of kyphotic alignment change after laminoplasty in patients with cervical myelopathy. Spine (Phila Pa 1976) 38 : E992-E997, 2013

32. Kwon SY, Shin JJ, Lee JH, Cho WH : Prognostic factors for surgical outcome in spinal cord injury associated with ossification of the posterior longitudinal ligament (OPLL). J Orthop Surg Res 10 : 94, 2015

33. Lee BJ, Park JH, Jeon SR, Rhim SC, Roh SW : Importance of the preoperative cross-sectional area of the semispinalis cervicis as a risk factor for loss of lordosis after laminoplasty in patients with cervical spondylotic myelopathy. Eur Spine J 27 : 2720-2728, 2018

34. Lee CK, Shin DA, Yi S, Kim KN, Shin HC, Yoon DH, et al. : Correlation between cervical spine sagittal alignment and clinical outcome after cervical laminoplasty for ossification of the posterior longitudinal ligament. J Neurosurg Spine 24 : 100-107, 2016

35. Lee DH, Kim H, Lee HS, Noh H, Kim NH, Hwang C, et al. : The Kappa line - a predictor of neurologic outcome after cervical laminoplasty. ISASS13 Oral Podium and Oral Poster Presentation; 2013 Apr 3-5; Vancouver, Canada. Rosemont (IL) : ISASS; 2013

36. Lee JS, Son DW, Lee SH, Kim DH, Lee SW, Song GS: The predictable factors of the postoperative kyphotic change of sagittal alignment of the cervical spine after the laminoplasty. J Korean Neurosurg Soc 60 : 577-583, 2017

37. Lee SH, Kim KT, Lee JH, Kang KC : Presentation \#32: posterior cervical spinal cord shift following posterior decompression and prediction of persistent anterior spinal cord compression using K-plane: a three dimensional modification of K-line on MRI. Spine Journal Meeting Abstracts 2016 : 155-157, 2016

38. Lee SH, Son DW, Lee JS, Kim DH, Sung SK, Lee SW, et al. : Differences in cervical sagittal alignment changes in patients undergoing laminoplasty and anterior cervical discectomy and fusion. Neurospine 15 : 91-100, 2018

39. Lee SH, Son DW, Lee JS, Sung SK, Lee SW, Song GS : Does extension dysfunction affect postoperative loss of cervical lordosis in patients who undergo laminoplasty? Spine (Phila Pa 1976) 44 : E456-E464, 2019

40. Li J, Zhang Y, Zhang N, Xv ZK, Li H, Chen G, et al. : Clinical outcome of laminoplasty for cervical ossification of the posterior longitudinal ligament with $\mathrm{K}$-line (-) in the neck neutral position but K-line (+) in the neck extension position: a retrospective observational study. Medicine (Baltimore) 96 : e6964, 2017

41. Li $X Y$, Kong C, Sun XY, Guo MC, Ding JZ, Yang YM, et al. : Influence of the ratio of $\mathrm{C} 2-\mathrm{C} 7 \mathrm{Cobb}$ angle to $\mathrm{T} 1$ slope on cervical alignment after laminoplasty. World Neurosurg 124 : e659-e666, 2019

42. Lin BJ, Hong KT, Lin C, Chung TT, Tang CT, Hueng DY, et al. : Impact of global spine balance and cervical regional alignment on determination of postoperative cervical alignment after laminoplasty. Medicine (Baltimore) 97 : e13111, 2018

43. Maruo K, Moriyama T, Tachibana T, Inoue S, Arizumi F, Daimon T, et al. : The impact of dynamic factors on surgical outcomes after double-door laminoplasty for ossification of the posterior longitudinal ligament of the cervical spine. J Neurosurg Spine 21 : 938-943, 2014

44. Masaki Y, Yamazaki M, Okawa A, Aramomi M, Hashimoto M, Koda M, et al. : An analysis of factors causing poor surgical outcome in patients with cervical myelopathy due to ossification of the posterior longitudinal ligament: anterior decompression with spinal fusion versus laminoplasty.

J Spinal Disord Tech 20 : 7-13, 2007

45. Matsuoka Y, Suzuki H, Endo K, Sawaji Y, Murata K, Nishimura H, et al. : Small sagittal vertical axis accompanied with lumbar hyperlordosis as a risk factor for developing postoperative cervical kyphosis after expansive open-door laminoplasty. J Neurosurg Spine 29 : 176-181, 2018

46. Matsuyama Y, Kawakami N, Yanase M, Yoshihara H, Ishiguro N, Kameyama T, et al. : Cervical myelopathy due to OPLL: clinical evaluation by MRI and intraoperative spinal sonography. J Spinal Disord Tech 17 : 401-404, 2004

47. Miyazaki M, Ishihara T, Notani N, Kanezaki S, Tsumura H : Relationship of T1 slope with loss of lordosis and surgical outcomes after laminoplasty for cervical ossification of the posterior longitudinal ligament. Clin Neurol Neurosurg 164 : 19-24, 2018

48. Ogawa Y, Toyama Y, Chiba K, Matsumoto M, Nakamura M, Takaishi H, et al. : Long-term results of expansive open-door laminoplasty for ossification of the posterior longitudinal ligament of the cervical spine. J Neurosurg Spine $1: 168-174,2004$

49. Oh JK, Hong JT, Kang DH, Kim SW, Kim SW, Kim YJ, et al. : Epidemiology of $C 5$ palsy after cervical spine surgery: a 21-center study. Neurospine 16 : 558-562, 2019

50. Oichi T, Oshima Y, Taniguchi Y, Matsubayashi Y, Chikuda H, Takeshita $\mathrm{K}$, et al. : Cervical anterolisthesis: a predictor of poor neurological out- 
comes in cervical spondylotic myelopathy patients after cervical laminoplasty. Spine (Phila Pa 1976) 41 : E467-E473, 2016

51. Oshima Y, Takeshita K, Taniguchi Y, Matsubayashi Y, Doi T, Ohya J, et al. : Effect of preoperative sagittal balance on cervical laminoplasty outcomes. Spine (Phila Pa 1976) 41 : E1265-E1270, 2016

52. Papavero L, Schmeiser G, Kothe R, Boszczyk B, Heese O, Kawaguchi Y, et al. : Degenerative cervical myelopathy: a 7-letter coding system that supports decision-making for the surgical approach. Neurospine 17 : 164-171, 2020

53. Parthiban J, Alves OL, Chandrachari KP, Ramani P, Zileli M : Value of surgery and nonsurgical approaches for cervical spondylotic myelopathy: WFNS Spine Committee recommendations. Neurospine 16 : 403-407, 2019

54. Rao H, Huang Y, Lan Z, Xu Z, Li G, Xu W : Does preoperative T1 slope and cervical lordosis mismatching affect surgical outcomes after laminoplasty in patients with cervical spondylotic myelopathy? World Neurosurg 130 : e687-e693, 2019

55. Sakai K, Yoshii T, Hirai T, Arai Y, Matsukura Y, Okawa A : The K-line tilt, a novel radiographic parameter of cervical sagittal balance, is a predictor of postoperative kyphotic deformity after laminoplasty for cervical myelopathy caused by ossification of the posterior longitudinal ligament. Proceedings of the 44th Annual Meeting of the Cervical Spine Research Society; 2016 Dec 1-3; Toronto, Canada. Brookfield (WI) : Milwaukee; 2017

56. Sakai K, Yoshii T, Hirai T, Arai Y, Torigoe I, Tomori M, et al. : Cervical sagittal imbalance is a predictor of kyphotic deformity after laminoplasty in cervical spondylotic myelopathy patients without preoperative kyphotic alignment. Spine (Phila Pa 1976) 41 : 299-305, 2016

57. Sakaura H, Ohnishi A, Yamagishi A, Ohwada T : Differences in postoperative changes of cervical sagittal alignment and balance after laminoplasty between cervical spondylotic myelopathy and cervical ossification of the posterior longitudinal ligament. Global Spine J 9 : 266-271, 2019

58. Satomi K, Nishu Y, Kohno T, Hirabayashi K : Long-term follow-up studies of open-door expansive laminoplasty for cervical stenotic myelopathy. Spine (Phila Pa 1976) 19 : 507-510, 1994

59. Schwartz JT, Gao M, Geng EA, Mody KS, Mikhail CM, Cho SK : Applications of machine learning using electronic medical records in spine surgery. Neurospine $16: 643-653,2019$

60. Seichi A, Takeshita K, Ohishi I, Kawaguchi H, Akune T, Anamizu Y, et al. : Long-term results of double-door laminoplasty for cervical stenotic myelopathy. Spine (Phila Pa 1976) 26 : 479-487, 2001

61. Sharma R, Borkar SA, Goda R, Kale SS : Which factors predict the loss of cervical lordosis following cervical laminoplasty? A review of various indices and their clinical implications. Surg Neurol Int 10 : 147, 2019

62. Sharma R, Borkar S, Katiyar V, Goda R, Phalak M, Joseph L, et al. : Interplay of dynamic extension reserve and $\mathrm{T} 1$ slope in determining the loss of cervical lordosis following laminoplasty: a novel classification system. World Neurosurg 136 : e33-e40, 2020

63. Shimokawa $\mathrm{N}$, Sato $\mathrm{H}$, Matsumoto $\mathrm{H}$, Takami T : Review of radiological parameters, imaging characteristics, and their effect on optimal treat- ment approaches and surgical outcomes for cervical ossification of the posterior longitudinal ligament. Neurospine 16 : 506-516, 2019

64. Suda K, Abumi K, Ito M, Shono Y, Kaneda K, Fujiya M : Local kyphosis reduces surgical outcomes of expansive open-door laminoplasty for cervical spondylotic myelopathy. Spine (Phila Pa 1976) 28 : 1258-1262, 2003

65. Suk KS, Kim KT, Lee JH, Lee SH, Lim YJ, Kim JS : Sagittal alignment of the cervical spine after the laminoplasty. Spine (Phila Pa 1976) 32 : E656-E660, 2007

66. Sun LQ, Li M, Li YM : Prediction of incomplete decompression after cervical laminoplasty on magnetic resonance imaging: the modified K-line. Clin Neurol Neurosurg 146 : 12-17, 2016

67. Tamai K, Suzuki A, Yabu A, Terai H, Hoshino M, Toyoda H, et al. : Clinical impact of cervical imbalance on surgical outcomes of laminoplasty: a propensity score-matching analysis. Clin Spine Surg 33 : E1-E7, 2020

68. Taniyama T, Hirai T, Yamada T, Yuasa M, Enomoto M, Yoshii T, et al. : Modified K-line in magnetic resonance imaging predicts insufficient decompression of cervical laminoplasty. Spine (Phila Pa 1976) 38 : 496501, 2013

69. Taniyama T, Hirai T, Yoshii T, Yamada T, Yasuda H, Saito M, et al. : Modified $\mathrm{K}$-line in magnetic resonance imaging predicts clinical outcome in patients with nonlordotic alignment after laminoplasty for cervical spondylotic myelopathy. Spine (Phila Pa 1976) 39 : E1261-E1268, 2014

70. Vaziri S, Lockney DT, Dru AB, Polifka AJ, Fox WC, Hoh DJ : Does ossification of the posterior longitudinal ligament progress after fusion? Neurospine 16 : 483-491, 2019

71. Wilson JRF, Badhiwala JH, Moghaddamjou A, Martin AR, Fehlings MG : Degenerative cervical myelopathy; a review of the latest advances and future directions in management. Neurospine 16 : 494-505, 2019

72. Yamazaki A, Homma T, Uchiyama S, Katsumi Y, Okumura H : Morphologic limitations of posterior decompression by midsagittal splitting method for myelopathy caused by ossification of the posterior longitudinal ligament in the cervical spine. Spine (Phila Pa 1976) 24 : 32-34, 1999

73. Yonenobu K, Abumi K, Nagata K, Taketomi E, Ueyama K : Interobserver and intraobserver reliability of the japanese orthopaedic association scoring system for evaluation of cervical compression myelopathy. Spine (Phila Pa 1976) 26 : 1890-1894; discussion 1895, 2001

74. Zhang JT, Li JQ, Niu RJ, Liu Z, Tong T, Shen Y : Predictors of cervical lordosis loss after laminoplasty in patients with cervical spondylotic myelopathy. Eur Spine J 26 : 1205-1210, 2017

75. Zileli $\mathrm{M}$ : Recommendations of WFNS Spine Committee. Neurospine $16: 383-385,2019$

76. Zileli M, Borkar SA, Sinha S, Reinas R, Alves ÓL, Kim SH, et al. : Cervical spondylotic myelopathy: natural course and the value of diagnostic techniques -WFNS Spine Committee recommendations. Neurospine $16: 386-402,2019$

77. Zileli M, Maheshwari S, Kale SS, Garg K, Menon SK, Parthiban J : Outcome measures and variables affecting prognosis of cervical spondylotic myelopathy: WFNS Spine Committee recommendations. Neurospine $16: 435-447,2019$ 